\title{
AC 2010-1379: ENGINEERING MANAGEMENT ACTIONS TAKEN AND CHANGES MADE BY MANUFACTURERS TO BECOME MORE COMPETITIVE
}

\section{William Loendorf, Eastern Washington University}

William R. Loendorf is currently an Associate Professor of Engineering \& Design at Eastern Washington University. He obtained his B.Sc. in Engineering Science at the University of Wisconsin - Parkside, M.S. in Electrical Engineering at Colorado State University, M.B.A. at the Lake Forest Graduate School of Management, and Ph.D. in Engineering Management at Walden University. He holds a Professional Engineer license and has 30 years of industrial experience as an Engineer or Engineering Manager at General Motors, Cadnetix, and Motorola. His interests include engineering management, technological literacy, and real-time embedded systems. 


\title{
Engineering Management Actions Taken and Changes Made by Manufacturers to Become More Competitive
}

\begin{abstract}
Remaining competitive in today's economic climate is a formidable task for all organizations. It is especially so for smaller organizations classified as job shops. For them the problem is even more complex due to limited resources including capital, equipment, and personnel. Many engineering management actions and changes have proven effective and are available for them to use. However, what are they actually doing to become more competitive? To answer that question a study was conducted in 2008 into one basic type of job shop; the American tool and die shops that fabricate molds, dies, and tools vital to the manufacturing process. The intent was to find out how they are reacting to the globalization of the tooling industry. The emphasis was on the methods, procedures, and processes that have already proven effective by American tool shops to enhance quality, increase efficiency, and streamline operations. This information is significant because it has an established record of success when implemented in real-world competitive situations and must be covered in the management courses included in the engineering and engineering technology curriculum. The findings indicate that American tool shops are using innovative technologies, updating machinery, and instituting new strategies. The tool shops making this transition are the adaptors creating new competitive advantages by revising their strategies to reflect competitive changes, offering products fitting into unique niches, supplying specialized customer services, and providing rapid delivery. The results from this study have been incorporated into engineering and engineering technology courses to better prepare graduates for careers in engineering management for manufacturing based industries.
\end{abstract}

\section{Introduction}

Foreign competition has had an extremely negative impact on American manufacturing in terms of cheaper and in some cases poorer quality tools. "Nearly three million manufacturing jobs have been lost since $2000 \ldots$... The estimate ... is that by the end of the decade, China's expansion in tool and die could cause the loss of 900,000 industrial jobs in the U.S." (Moncrieff ${ }^{22}, 2006$, p. 3). Because the tooling industry utilizes a substantial technological component built upon an underlying engineering base the impact of these job losses would be extremely detrimental to the entire American industrial sector in terms of its intellectual capacity, skilled workforce, and ability to compete successfully.

A lack of resources at most tool shops makes it difficult to remain competitive (Michigan Economic Development Corporation ${ }^{21}$, 2005). Since limited time, manpower, and capital are available to work on these critical business issues quick fixes that may or may not actually improve the situation are often implemented (Summers $\left.{ }^{25}, 2005\right)$. "However, these quick fixes are just that - a quick fix of a problem for the short term; they simply allow time for a long-term solution to be found" (Summers ${ }^{25}, 2005$, p. 290). Due to the lack of resources, many of these band-aid solutions are likely to become permanent. 
The purpose of this 2008 study (Loendorf ${ }^{19}, 2008$ ) was to survey and describe the actions undertaken by the American tooling industry to become more competitive while successfully responding to increased worldwide business and manufacturing pressure. The intent was to find out how they are reacting to the globalization of the tooling industry. This includes examining what tool shops are doing to offset this increased competition from their foreign counterparts along with the methods, processes, and techniques that companies are using successfully.

Engineering managers are responsible for the application of engineering principles to the planning and operational management of industrial and manufacturing operations. Therefore it is important for engineering managers to know what actions and changes have an established record of success when implemented in real-world competitive situations. With this objective in mind, the results from this study have been incorporated into a variety of engineering and engineering technology courses in order to better prepare graduates for careers in engineering management for manufacturing based industries. This knowledgebase is also transferable to other American tool and die shops, job shops, and other manufacturing organizations to improve their competitive position.

\section{Theoretical or Conceptual Support}

The literature contains many theoretical methods to enhance production flow by improving processes, optimizing schedules, and sequencing work for job shops. There are also many proven concepts from quality control and engineering management that can be applied to improve an organization's competitive position.

$\operatorname{Berg}^{4}$ (1998) discovered four main modes of adapting to the new competitive environment in the machine tool industry: maintaining, deploying, developing, and diverging. Kalafsky ${ }^{16,17}$ (2002, 2006) showed that the role of location plays a significant part in a tool firm's survival with the customer typically in close proximity. Additional research on the tooling industry was carried out by the Center of Automotive Research (Baron ${ }^{3}$, 2005), indicating that a transformation in the tooling industry is leading to new significant trends improving its ability to compete.

Delays exist between processes that often go undetected and unevaluated. This entire supply chain process begins with the request for quote (RFQ) and ends with delivery of the finished product to the customer. Many steps in between can and often do cause delays. Of critical importance is the total cumulative elapsed time from start to finish of all the processes required to get the product to the customer. Bozzone ${ }^{5,6}$ (2001) has named this phenomenon the theory of delays. The objective today is speed. Those tool shops that can get a quality product to their customer faster and cheaper will win while those that are slower will lose.

The tooling industry is a typical make-to-order (MTO) business characterized by an orderpenetration-point (OPP) at the beginning of the production process. This early OPP is a strategic advantage allowing for a high degree of product customization (Spring \& Dalrymple ${ }^{24}, 2000$ ). However, customization often results in longer lead times than make-to-stock (MTS) products due to shop floor routings that are typically unusual and non-standard (Stevenson, Hendry, \& $\operatorname{Kingsman}^{26}, 2005$ ). Because of this customization, MTO firms experience a unique set of scheduling difficulties. 
Job shop scheduling is a very complex problem full of uncertainties including rush orders, machine failures, and many others. The movement of materials through the manufacturing process transforming raw materials or inputs into outputs is termed production flow. Incorporated into this process are delays waiting for equipment availability, inspections, moving of work in process (WIP), and numerous other causes. By breaking this process down into individual tasks and performing each of them more efficiently, the entire production flow can be streamlined.

Many theoretical scheduling methods exist including manufacturing resource planning (MRP) (Stevenson, Hendry, \& Kingsman ${ }^{26}, 2005$ ), theory of constraints (TOC) (Mabin \& Balderstone ${ }^{20}$, 2003), longest path problem (LPP) (Choi \& Yang $\left.{ }^{9}, 2005\right)$, disruptive (Alvarez \& Diaz $\left.{ }^{1}, 2004\right)$, dynamic (Choi \& You $^{8}, 2006$ ), and parallel work flow (Artigues, Billaut, \& Esswein ${ }^{2}, 2005$ ). Other methods include utilizing buffers (Litchfield $\left.{ }^{18}, 1995\right)$, batches (Toba $\left.{ }^{29}, 2005\right)$, fuzzy algorithms (Celano, Costa, \& Fichera ${ }^{7}, 2003$ ), and response time (Thiagarajan \& Rajendran ${ }^{28}$, 2005). Additional methods using weighted sum (Dawande, Gavirneni, \& Rachamadugu ${ }^{10}, 2006$ ), priority-dispatching rule (Weng \& Halying ${ }^{31}$, 2006), throughput (Tavakkoli-Moghaddam \& Daneshmand-Mehr ${ }^{27}, 2005$ ), and machine capabilities (Wu and $\mathrm{Weng}^{32}, 2005$ ) have also been suggested. The proper scheduling of work is of paramount importance with tool shops often treating each order as a mini project.

By simply doing small things more effectively, big gains in efficiency can often be achieved. Reassessing, improving, or speeding up common everyday activities can lead to a competitive advantage. These frequently overlooked activities are so familiar and ordinary that they could not possibly make a difference, but in many instances, they can.

Deanovic $^{11}$ (2005) developed a rapid response system for returning accurate quotes quickly offering a better chance of winning the business; this is especially true with a rush or high priority order. Rashdi ${ }^{23}$ (1996) stated three critical factors in a MTO company's planning and control system: assigning due dates to customer orders, timing for releasing a job to the shop floor, and setting the priority of the job for processing. Research by Destefani ${ }^{12}$ (2005) found that three management principles gave job shops the best prospects to improve their competitiveness and succeed. They included focus on reducing delivery time, bring critical outsourced production processes back in-house, and adopt the continuous manufacturing flow philosophy. Any tool shop could easily make these improvements without increasing overhead.

Many advantages result from performing tasks more efficiently; thus improving the competitiveness of an organization. This includes every aspect of the tool shop from management, to sales, to scheduling, to production, and even delivery. Overlook nothing, no matter how routine or ordinary the process may seem. However, simply making changes does not always result in improvements.

\section{Scope}

The scope of this 2008 study (Loendorf ${ }^{19}$, 2008) included only American tool and die shops. Due to the wide variability of tool shops in terms of size (i.e., number of employees, sales volume, 
financial condition, etc, ) it is difficult to determine exactly how many of them are still operating in America. However, the most accurate count of American tool and die shops was obtained from professional associations. The National Tooling \& Machining Association ${ }^{15}$ (NTMA) has approximately 1,700 American manufacturing members ("History of NTMA," 2006). The Tooling Manufacturing \& Technologies Association, formerly known as the Michigan Tooling Association, has over 600 member organizations in the State of Michigan alone (Harrison ${ }^{14}$, 2007). This figure can be extrapolated to about 1,800 American organizations by considering that The Center for Automotive Research reported that one third of all tool shops are located in the State of Michigan (Baron ${ }^{3}$, 2005). Harrison ${ }^{14}$ (2007) also stated that overall there were 1,520 tool and die makers in 2002 located in Michigan. This figure roughly extrapolates to 4,500 tool shops across America. However, not all of them are still in existence and many simply do not join professional associations.

The research design was an exploratory mixed model design. The study was primarily qualitative with some quantitative aspects resulting in a mixture of both models. Participants received electronically a self-administered survey. By using random selection, organizations of all sizes in the tooling industry located across America became eligible for study. Six hundred firms contacted from the available pool of approximately 1,700 NTMA members yielded 94 sources of survey data. Since the tooling industry is closely tied to the durable goods industry it was highly anticipated that the majority of the participants were from the automotive and aerospace industries.

The survey data gathered was analyzed using descriptive statistics to "provide simple summaries about the sample and the measures" (Trochim ${ }^{30}, 2001$, p. 268). "Typical statistics include rankings (best to worst), simple frequency counts (how many), [and] cross-classifications (contingent frequencies)" (Hair, Babin, Money, and Samouel ${ }^{13}$, 2003, p. 61). The results use frequency distribution tables to list the possible answers from each question and how many respondents selected each one. Computed percentages presented the data and indicated the rate of occurrence or use of each of the courses of actions. Together these factors indicated the dominant characteristics of the tooling industry along with the leading factors currently used to increase their competitive position.

\section{Demographics of Tool Shop Respondents}

The demographics of the responding tool shops indicate that they were truly small businesses with almost $75 \%$ employing less than 60 workers. For almost two-thirds of the tool shops their annual sales were in the 1 to 10 million-dollar vicinity. Sales trends over the past three years have decreased for over $35 \%$ of the tool shops, remained the same for over $21 \%$, while $43 \%$ have noticed some increase. Nearly a third of the respondents reported no international sales while over a half were in the $1 \%$ to $20 \%$ bracket and over one-tenth were in the $21 \%$ to $60 \%$ range. The impact on business for almost $94 \%$ of the organizations has been negative, slightly over $5 \%$ have experienced no change, and just over $1 \%$ had a small positive effect. Over $38 \%$ of the tool shops are growing while $28 \%$ are shrinking with over $31 \%$ in the stable or steady state mode. This data indicates that American tool shops are truly a domestic industry that is undergoing change and transformation. 


\section{Results}

American tool shops have taken actions and made changes in order to become more competitive. Twenty-seven actions and changes were selected for this study from pretest results. Table 1 shows those actions either considered, planned, or implemented both by percentage and number of selections. Since multiple selections were allowed all of the possible actions were selected numerous times, which is consistent with the three management principles reported by Destefani $^{12}$ (2005). The percentages of already implemented actions in almost every instance exceeded the percentages for planned or considered actions or changes. The exceptions included focus on fewer tools along with eliminate disruptions/interferences.

Table 1

Actions Taken to Counteract Imported Tools

\begin{tabular}{|c|c|c|c|}
\hline Action (Number of responses) & $\begin{array}{l}\text { Considered } \\
\% \text { (Number) }\end{array}$ & $\begin{array}{c}\text { Planned } \\
\% \text { (Number) }\end{array}$ & $\begin{array}{l}\text { Implemented } \\
\% \text { (Number) }\end{array}$ \\
\hline Improve cost structure (57) & $17.5(10)$ & $38.6(22)$ & $43.9(25)$ \\
\hline Improve pricing structure (52) & $28.9(15)$ & $23.1(12)$ & $48.1(25)$ \\
\hline Consolidate operations (26) & $42.3(11)$ & $15.4(4)$ & $42.3(11)$ \\
\hline Focus on fewer tools (29) & $48.3(14)$ & $13.8(4)$ & $37.9(11)$ \\
\hline Eliminate unnecessary processes (56) & $12.5(7)$ & $19.6(11)$ & $67.9(38)$ \\
\hline Eliminate wasted time \& materials (54) & $5.5(3)$ & $29.6(16)$ & $64.8(35)$ \\
\hline Enhance technical capabilities (56) & $12.5(7)$ & $19.6(11)$ & $67.9(38)$ \\
\hline Purchase new technologies (52) & $17.3(9)$ & $13.5(7)$ & $69.2(36)$ \\
\hline Purchase new machines (55) & $16.4(9)$ & $7.3(4)$ & $76.4(42)$ \\
\hline Purchase new CNC equipment (61) & $13.1(8)$ & $8.2(5)$ & $78.7(48)$ \\
\hline Redesign production workflow (45) & $13.1(6)$ & $35.6(16)$ & $51.0(23)$ \\
\hline Remove production bottlenecks (46) & $15.2(7)$ & $34.8(16)$ & $50.0(23)$ \\
\hline Improve the quality of your tools (37) & $18.9(7)$ & $21.6(8)$ & $59.5(22)$ \\
\hline Improve scheduling of work (47) & $14.9(7)$ & $34.0(16)$ & $51.1(24)$ \\
\hline Improve worker training programs (47) & $21.3(10)$ & $34.0(16)$ & $44.7(21)$ \\
\hline Streamline procedures (41) & $14.6(6)$ & $24.4(10)$ & $61.0(25)$ \\
\hline Eliminate disruptions/interferences (32) & $25.0(8)$ & $43.8(14)$ & $31.2(10)$ \\
\hline Identify time and cost savings (44) & $13.6(6)$ & $38.6(17)$ & $47.7(21)$ \\
\hline Improve on-time deliveries (47) & $4.3(2)$ & $40.4(19)$ & $55.3(26)$ \\
\hline Improve customer flexibility (35) & $31.4(11)$ & $11.4(4)$ & $57.1(20)$ \\
\hline Improve customer satisfaction (42) & $4.8(2)$ & $21.4(9)$ & $73.8(31)$ \\
\hline Improve customer response time (48) & $6.3(3)$ & $31.3(15)$ & $62.5(30)$ \\
\hline Reduce order cycle time (42) & $19.0(8)$ & $35.7(15)$ & $45.2(19)$ \\
\hline Reduce production cycle time (45) & $15.6(7)$ & $40.0(18)$ & $44.4(20)$ \\
\hline Reduce inventory levels (34) & $26.5(9)$ & $23.5(8)$ & $50.0(17)$ \\
\hline Reduce machine downtime (39) & $12.8(5)$ & $30.8(12)$ & $56.4(22)$ \\
\hline Reduce machine setup time (48) & $14.6(7)$ & $41.7(20)$ & $43.8(21)$ \\
\hline
\end{tabular}

Note, Respondents could select multiple actions to counter imported tools. 
The actions receiving the highest number of total responses were to purchase new $\mathrm{CNC}$ equipment, improve cost structure, eliminate unnecessary processes, enhance technical capabilities, and purchase new machines. Together these indicate financial improvements tied to enhancements in technology and machinery. The actions with the lowest number of responses were to consolidate operations, focus on fewer tools, and eliminate disruptions/interferences. However, these factors may be related to one of the top selections eliminate unnecessary processes.

Over $56 \%$ of the total selections were made in the already implemented column indicating that a lot of actions and changes have already been made. The most frequently implemented actions by percentages were: purchase new $\mathrm{CNC}$ equipment, purchase new machines, improve customer satisfaction, purchase new technologies, and enhance technical capabilities. In three of these cases, new technologies or machines have been implemented while in the other two they enhanced operations or improved value to their customers. These actions were also reflected in the next five highest selections. When ordered by the total number of selections the ranking changes slightly to purchase new CNC equipment, purchase new machines, enhance technical capabilities, eliminate unnecessary processes, and purchase new technologies. Once again the focus is on new technologies and equipment along with speeding up operations.

Actions planned accounted for $27 \%$ of the overall selections indicating that more work still needs to be done. Even though improvements have been made, many tool shops are not where they really want to be in terms of their ability to compete. The top four actions planned by percentages were to eliminate disruptions/interferences, reduce machine setup time, improve ontime deliveries, and reduce production cycle time. They were followed by a tie between improve cost structure and identify time and cost savings. These actions indicate a need to improve the speed at which things are accomplished. Continued improvements in throughput to streamline operations are reflected in these results. Looking at the listing in terms of total number of selections rearranges it some to include: improve cost structure, reduce machine setup time, improve on-time deliveries, reduce production cycle time, and identify time and cost savings. This sequence also reflects improving operational efficiency and cutting costs.

Almost $17 \%$ of the total selections were made in the actions considered column. This signifies that some actions were considered but not realized due to other actions with higher priorities, lack of resources, or for other reasons. For those actions under consideration, the top responses by percentage were to focus on fewer tools (or reduce the number of product offerings), consolidate operations, improve customer flexibility, improve pricing structure, and reduce inventory levels. All of these actions being considered reflect a need to reexamine how the organization does business including downsizing, reducing costs, and improving quality. A small variation in the list occurs when viewed by the total number of selections with the top selections becoming: improve pricing structure, focus on fewer tools (or reduce the number of product offerings), improve customer flexibility, consolidate operations, and improve worker training programs. Even with a different last action, the list still reflects the same objectives.

Ordered by percentages or total number of selections, four of the top five actions (either considered, planned, or implemented) selected involved some aspect of enhancing capabilities 
through the use of new technologies. For three of these selections that meant purchasing new machinery while the fourth was enhancing technologies. These are perhaps the quickest ways to improve efficiency and streamline operations; however they come with a cost. Many tool shops may not be willing or financially able to spend the large sums of money required to purchase or lease this new equipment. This step could easily put their future in jeopardy. However, it is seen as a rapid way to become more competitive and many tool shops are taking that route.

The impact shown in Table 2 from these competitive changes was for the most part very positive.

Table 2

Impact from the Already Implemented Changes

\begin{tabular}{|c|c|c|c|}
\hline $\begin{array}{l}\text { Implemented change } \\
\text { (Number of responses) }\end{array}$ & $\begin{array}{c}\text { Positive } \\
\text { impact } \\
\% \text { (Number) }\end{array}$ & $\begin{array}{c}\text { No } \\
\text { impact } \\
\% \text { (Number) }\end{array}$ & $\begin{array}{l}\text { Negative } \\
\text { impact } \\
\% \text { (Number) }\end{array}$ \\
\hline Improve cost structure (39) & $66.7(26)$ & $28.2(11)$ & $5.1(2)$ \\
\hline Improve pricing structure (39) & $61.5(24)$ & $30.8(12)$ & $7.7(3)$ \\
\hline Consolidate operations (20) & $45.0(9)$ & $55.0(11)$ & $0.0(0)$ \\
\hline Focus on fewer tools (19) & $31.6(6)$ & $47.4(9)$ & $21.1(4)$ \\
\hline Eliminate unnecessary processes (42) & $81.0(34)$ & $19.0(8)$ & $0.0(0)$ \\
\hline Eliminate wasted time \& materials (37) & $75.7(28)$ & $24.3(9)$ & $0.0(0)$ \\
\hline Enhance technical capabilities (41) & $73.2(30)$ & $14.6(6)$ & $12.2(5)$ \\
\hline Purchase new technologies (43) & $83.7(36)$ & $11.6(5)$ & $4.7(2)$ \\
\hline Purchase new machines (44) & $84.1(37)$ & $9.1(4)$ & $6.8(3)$ \\
\hline Purchase new CNC equipment (50) & $82.0(41)$ & $12.0(6)$ & $6.0(3)$ \\
\hline Redesign production workflow (30) & $70.0(21)$ & $20.0(6)$ & $10.0(3)$ \\
\hline Remove production bottlenecks (30) & $76.7(23)$ & $23.3(7)$ & $0.0(0)$ \\
\hline Improve the quality of your tools (26) & $65.4(17)$ & $34.6(9)$ & $0.0(0)$ \\
\hline Improve scheduling of work (28) & $82.1(23)$ & $17.9(5)$ & $0.0(0)$ \\
\hline Improve worker training programs (30) & $60.0(18)$ & $30.0(9)$ & $10.0(3)$ \\
\hline Streamline procedures $(28)$ & $67.9(19)$ & $25.0(7)$ & $7.1(2)$ \\
\hline Eliminate disruptions/interferences (16) & $62.5(10)$ & $37.5(6)$ & $0.0(0)$ \\
\hline Identify time and cost savings (28) & $71.4(20)$ & $25.0(7)$ & $3.6(1)$ \\
\hline Improve on-time deliveries (29) & $69.0(20)$ & $27.6(8)$ & $3.4(1)$ \\
\hline Improve customer flexibility (26) & $61.5(16)$ & $30.8(8)$ & $7.7(2)$ \\
\hline Improve customer satisfaction (33) & $72.7(24)$ & $27.3(9)$ & $0.0(0)$ \\
\hline Improve customer response time $(31)$ & $67.7(21)$ & $29.0(9)$ & $3.2(1)$ \\
\hline Reduce order cycle time (23) & $60.9(14)$ & $30.4(7)$ & $8.7(2)$ \\
\hline Reduce production cycle time (27) & $66.7(18)$ & $33.3(9)$ & $0.0(0)$ \\
\hline Reduce inventory levels (24) & $54.2(13)$ & $45.8(11)$ & $0.0(0)$ \\
\hline Reduce machine downtime (29) & $58.6(17)$ & $37.9(11)$ & $3.4(1)$ \\
\hline Reduce machine setup time (31) & $74.2(23)$ & $22.6(7)$ & $3.2(1)$ \\
\hline
\end{tabular}

Note, Respondents could select multiple implemented changes to counter imported tools. 
Almost $70 \%$ of the implemented changes had a positive impact, a little more than $25 \%$ had no impact, and just fewer than 5\% had a negative impact. Over $95 \%$ of the changes implemented had no adverse effects leading to the implication that change is good even if some of the actions had no impact on the business. All but two of the already implemented changes have made a positive impact that was larger than the no impact and negative impact percentages combined. Only the actions to consolidate operations and focus on fewer tools had higher no impact percentages than positive impact. In fact, they had the two highest no impact percentages. Consolidating operations had no negative impact but had the largest no impact percentage. All of the negative impact percentages were low with the exception of focus on fewer tools, which was by far the highest in that category.

The already implemented changes with the highest number of total responses were to purchase new $\mathrm{CNC}$ equipment, purchase new machines, purchase new technologies, eliminate unnecessary processes, and enhance technical capabilities. These changes included financial improvements tied to enhancements in technology and machinery. The emphasis is clearly on new equipment and technologies that could improve their ability to compete. The actions with the lowest number of responses were to eliminate disruptions/interferences, focus on fewer tools, and consolidate operations. These choices reflect a reluctance to downsize operations or change the way things have always been done. Although gallant this unwillingness to face reality and prepare for future competition may well lead to the organization going out of business or shrinking to a shadow of its former self.

The changes resulting in the highest positive impact by percentages were to purchase new machines, purchase new technologies, improve scheduling of work, purchase new CNC equipment, and eliminate unnecessary processes. The list is only slightly changed when ranked by the highest number of selections and becomes: purchase new CNC equipment, purchase new machines, purchase new technologies, eliminate unnecessary processes, and enhance technical capabilities. These actions indicate that the biggest impact to the organization can be obtained by purchasing new technologies and equipment along with improving workflow and scheduling. All of the actions taken had a positive impact for over half of the respondents with only two exceptions.

Consolidate operations and focus on fewer tools led all other actions by percentages in the no impact category. They were followed by reduce inventory levels, reduce machine downtime, eliminate disruptions/interferences, and improve the quality of your tools. This indicates that downsizing the operation in any way along while improving the quality of your product, when quality is expected, had no impact on the organization. When ordering the actions by the total number of selections it becomes a little different. Now improving pricing structure leads the list followed by a four way tie that includes improve cost structure, reduce machine downtime, reduce inventory levels, and consolidate operations. This list also shows that improving financial aspects, improving reliability of equipment, and downsizing really had no impact as well.

Ten of the actions had no negative impact at all and only two actions were selected more than three times. Another six had a negative impact of less than 5\%. The highest actions with a negative impact by percentages were: focus on fewer tools, enhance technical capabilities, 
redesign production workflow, improve worker training programs, and reduce order cycle time. By viewing the negative impact related to the number of total selections the top two become: enhance technical capabilities and focus on fewer tools. They were followed by a five-way tie with only three selections each. This shows that even with some negative impact associated with the change, overall they had a larger more positive component. However, this could also indicate hidden implementation problems associated with personnel, management, capital, and time.

The respondents had the opportunity to offer their input on other competitive actions along with their impact. They could relate what was working for them specifically. A number of pertinent comments were received offering further insight into possible ways to become more competitive:

1. One of our biggest improvements was the purchase and implementation of simulation software. We are quoting and tooling to produce parts that would have been very difficult and expensive to design, build, develop, debug, and get approved.

2. Offer one-on-one contact with clients, something overseas competitors can't do effectively.

3. Offer custom-made products to client specifications, something large-volume overseas competitors can't do effectively.

4. Improvements do not keep pace with rising external costs for materials and employee benefits while stiffer price competition reduces selling prices. It is like we are on a treadmill that keeps speeding up. We are running faster to stay in the same place.

5. Our customers will not cooperate with us. They don't care if they make our job harder to do. They only care about themselves.

6. Every time we replace equipment a better machine is offered before we can pay off the first one. There is not enough money to stay on the cutting edge.

7. When you are competing against a country that is subsidized by their government, manipulates their currency, has no regard for worker safety or the environment, and pays workers a fraction of the cost per hour the solution is not floor improvements and investment. We cannot compete with that. As the volume of work decreases, our actual cost per hour increases.

8. We are on a true, Toyota Production System "Lean Journey," which we began in July this year. We are at the midpoint of Phase 1, the first six months of an expected three-year project. So far we have made great strides considering the short time. If we achieve target of $15 \%$ cost and lead time reduction by the end of January our Lean consultant will be assigned the next phase in this Die Factory System.

9. Use of digital product definition and model based definition to drive the manufacturing process and inspection, development of automation to assist in readying models for manufacturing and entry into ERP system.

10. Many items have already been implemented. They produced significant results when they were originally implemented. We now need to focus on other areas to get direct results.

Problems encountered included foreign governments subsidizing the tool industry, countries with lower wages, poor customer cooperation, lack of capital to purchase new equipment or technologies, and improvements not keeping pace with costs. Ways to obtain a competitive edge included one-on-one contact with clients, producing custom-made products to client specifications, and using new computer automation techniques. The continual need for improvement is noted along with the search for new ways to get better results. All together these 
suggest offering customized services that far away suppliers cannot, using new technologies, continual improvement, and trying to compete on an uneven playing field. However, the cost of new technologies may just be out of reach for many tool shops.

\section{Implementation}

Many engineers will become managers during some point in their career. Engineering managers combine management expertise with engineering knowledge to lead teams, departments, and companies in highly technical tasks. Most engineering managers focus on product development, materials management, production processes, and workforce reliability. Management engineers apply engineering principles to the planning and operational management of industrial and manufacturing operations.

The Department of Engineering \& Design offers degrees in Electrical Engineering, Computer and Mechanical Engineering Technology, Design, Manufacturing, Applied Technology, and Construction Management. The primary goal is to provide students with the technical background required for successful careers in industry and business. The coursework within each program offers experiences in real-world situations that enhance the preparation of graduates.

Results from this study have already been incorporated into courses that include: Problem Analysis and Design; Machine Tool; Computer-Aided Design; Project Management; Quality Assurance; Engineering Economics; Environmental Engineering; Engineering Ethics, Contracts, and Patents; Industrial Safety Engineering; Computing Systems; and Technology in World Civilization. The findings from this study have also been successfully incorporated into the Senior Engineering Capstone, Senior Capstone: Production Laboratory, and Senior Project courses, along with the Industrial Internship Program.

This integration has occurred in many facets of these courses. The textbook readings, lectures, and discussions were updated in order to emphasize the findings from the study. In addition homework assignments, case studies, and real world experiences derived from the study were included as individual or group exercises.

Homework projects and case studies related to applying these proven methods, procedures, and processes to enhance quality, increase efficiency, and streamline operations were developed and implemented for the abovementioned upper division courses. In each instance, the students apply their knowledge of these techniques to particular projects and analyze their effectiveness. They are also asked to suggest further improvements along with how they might be implemented.

In addition, case studies were developed from the study's findings and used as an integral part of the student's learning experience. These exercises challenged the student's to directly apply what they were learning to actual events that have occurred and develop a plan for resolving the issues. The lecture and discussion aspects of the courses were enhanced by adding a case study component as well.

A slightly different approach was used to apply the knowledge obtained from this study in the Industrial Internship Program. Here, the students are asked to examine their employer's 
competitive position in terms of operations and manufacturing. Then analyze their effectiveness, recommend improvements, and if feasible implement them. A final report is required that reviews the effectiveness of the improvements made in comparison to what was previously used. This real-world application has proven to be very useful to the student's employers leading to many operational and production changes. Letters of support have also been received from the employers for continuance of this hands-on approach to engineering experience.

These assignments and case studies go beyond textbook knowledge and add a real-world aspect to the study of engineering management techniques. The objective is to prepare the students for the challenges they will face during their professional careers. These future engineering managers will graduate with enhanced skills that are absolutely essential in our challenging economic environment and can be used to keep their chosen employer competitive.

\section{Conclusions}

The 94 respondents considered 27 possible actions to take and changes to make (Table 1) and collectively made 1,217 selections. The number of actions selected by each tool shop ranged from a low of five to a high of 19. This signifies that each tool shop has considered, planned, or implemented a variety of actions to improve their competitive position.

The most frequently selected actions showed a move toward enhancements in technology, machinery, and financial controls while the least often selected were to downsize or consolidate operations. The already implemented actions reinforced the move to new technologies and machines while tightening financial controls. Automation of activities became a quick fix to increase productivity and lower costs. Henry Ford's first assembly line utilized this strategy. However, the expense involved may have redirected some tool shops to alternative less costly solutions. This action was consistent with comments received from the respondents. The actions planned focused on improving the speed of operations to reduce costs and enhance customer satisfaction. Meanwhile, actions under consideration revolved around consolidating operations, reducing costs, and improving performance.

The impact from the already implemented changes (Table 2) was for the most part extremely positive. In fact, all but two had a positive impact larger than the no impact and negative impact percentages combined. The changes already implemented by purchasing new technologies and equipment along with improving workflow and scheduling have made a positive difference. Downsizing operations and improving quality had no impact on competitive position. Approximately $60 \%$ of the actions implemented had a negative impact less than $5 \%$ of the time. Selection of the highest negative impacting action by only $21 \%$ of the respondents indicated that in almost $80 \%$ of its implementations there was either no impact $(47 \%)$ or a positive impact $(32 \%)$.

Comments received from the respondents reinforced these conclusions. New equipment in terms of both software and hardware was making a substantial difference. Meanwhile, offering services like custom-made products and one-on-one contact with customers had a positive impact.

Supporting customers in ways that far away competitors cannot has also created new and unique 
opportunities. Even though tool shops have implemented many changes, many problems remain to be resolved.

The findings from this study indicate that the American tool industry has made and will continue to take responsive actions in terms of changes in the way it does business and manufactures products. Tool shops are continually searching for new ways to improve performance, increase efficiency, and improve quality. They are using innovative technologies, machines, and techniques while applying other methods of automation in order to produce products faster, cheaper, and better than in the past. The tool shops making this transition are the adaptors creating new competitive advantages while looking ahead for market changes, emerging trends, and new opportunities. Their strategy, undergoing constant revision, reflects competitive changes by finding and offering products fitting into unique niches utilizing new technologies, dedicated processes, special customer services, and rapid delivery. The tool shops making this transformation have not only learned to survive in today's global economy but to thrive and prosper in it.

Valuable information was obtained from this study concerning the changes being made by manufacturers to improve their competitive position. These results have been incorporated into the educational process for engineering and engineering technology students. The objective is to better prepare graduates for careers in engineering management for manufacturing based industries.

\section{Bibliography}

1. Alvarez, E., \& Diaz, F. (2004). An application of a real-time scheduling system for turbulent manufacturing environments. Robotics \& Computer Integrated Manufacturing, 20(6), 485-494.

2. Artigues, C., Billaut, J. C., \& Esswein, C. (2005). Maximization of solution flexibility for robust shop scheduling. European Journal of Operational Research, 165(2), 314-328.

3. Baron, J. (2005, November). Automotive \& tooling global trends. TIFA Symposium on Automotive Tooling Industry in Transition, Melbourne, Victoria. Retrieved from http://www.cargroup.org

4. Berg, D. M. (1998). Retooling for a globalized market: Adaptation in the United States machine tool industry. Dissertation Abstracts International, 59(02), 547. (AAT 9823805)

5. Bozzone, V. (2001). The theory of delays. Retrieved from http://www.deltadynamicsinc.com

6. Bozzone, V. (2002). Speed to market: Lean manufacturing for job shops ( $2^{\text {nd }}$ ed.). New York: AMACOM.

7. Celano, G., Costa, A., \& Fichera, S. (2003). An evolutionary algorithm for pure fuzzy flow shop scheduling problems. International Journal of Uncertainty, Fuzziness \& Knowledge-Based Systems, 11(6), 655-669.

8. Choi, B. K., \& You, N. K. (2006). Dispatching rules for dynamic scheduling of one-of-a-kind production. International Journal of Computer Integrated Manufacturing, 19(4), 383-392.

9. Choi, S. H., \& Yang, F. Y. (2005). Quick value-setting algorithms for the longest path problem of job shop scheduling. Journal of Manufacturing Technology Management, 16(8), 956-972.

10. Dawande, M., Gavirneni, S., \& Rachamadugu, R. (2006). Scheduling a two-stage flowshop under makespan constraint. Mathematical and Computer Modeling, 44(1/2), 73-84.

11. Deanovic, D. (2005). Fast, accurate quotes aid job shops. Manufacturing Engineering, 134(1), 32-36.

12. Destefani, J. (2005). Three simple rules for job-shop success. Manufacturing Engineering, 134(6), 75-82.

13. Hair, J. F., Jr., Babin, B., Money, A. H., \& Samouel, P. (2003). Essentials of business research methods. Hoboken, NJ: Wiley.

14. Harrison, S. (2007). Tooling group, in dispute with Engler-led group, goes national. Crain's Detroit Business, 23(2), 1-2. 
15. History of NTMA (2006). National Tooling \& Machining Association. Retrieved from https://www.ntma.org/eweb/dynamicpage.aspx? webcode=AboutSecondary\&key2=8a3da4f8-8cbe-452e-a94c$1 \mathrm{ad} 47 \mathrm{~d} 3 \mathrm{a} 6112 \&$ Site $=$ NTMA

16. Kalafsky, R. V. (2002). The role of location in a mature manufacturing sector: An examination of the United States machine tool industry. Dissertation Abstracts International, 63(05), 1947. (AAT 3052518)

17. Kalafsky, R. V. (2006). Performance and practice: Examining the machine tool industries of Japan and the United States. Journal of Economics \& Social Geography, 97(2), 178-194.

18. Litchfield, J. A. (1995). Improving job shop performance through utilization of system information in process queue management under transfer batching. Dissertation Abstracts International, 57(02), 762. (AAT 9619859)

19. Loendorf, W. R. (2008). Transition of the tooling industry in a competitive global environment. Dissertation Abstracts International, 69(03). (AAT 3297978)

20. Mabin, V. J., \& Balderstone, S. J. (2003). The performance of the theory of constraints methodology: Analysis and discussion of successful TOC applications. International Journal of Operations and Production Management, 23(6), 568-595.

21. Michigan Economic Development Corporation (2005). Michigan tool industry. Retrieved from http://www.michigan.org/medc/cm/attach/655B5D82-04D0-4C32-ACB9E83C3AFBBD03/ToolingIndustry030721.pdf

22. Moncrieff, L. S. (2006). Testimony on China's impact on the U.S. auto and auto parts industries before the U.S. China Economic \& Security Review Commission July 17, 2006.

23. Rashdi, P. R. S. (1996). The manufacturing, planning and control of make-to-order companies. Dissertation Abstracts International, 58(02), 714. (AAT C539984)

24. Spring, M., \& Dalrymple, J. (2000). Product customization and manufacturing strategy. International Journal of Operations and Production Management, 20(4), 441-467.

25. Summers, D. C. S. (2005). Quality management: Creating and sustaining organizational effectiveness. Upper Saddle River, NJ: Pearson Education.

26. Stevenson, M., Hendry, L. C., \& Kingsman, B. G. (2005). A review of production planning and control: The applicability of key concepts to the make-to-order industry. International Journal of Production Research, 43(5), 869-898.

27. Tavakkoli-Moghaddam, R., \& Daneshmand-Mehr, R. (2005). A computer simulation model for job shop scheduling problems minimizing makespan. Computers \& Industrial Engineering, 48(4), 811-823.

28. Thiagarajan, S., \& Rajendran, C. (2005). Scheduling in dynamic assembly job-shops to minimize the sum of weighted earliness, weighted tardiness and weighted flowtime of jobs. Computers \& Industrial Engineering, 49(4), 463-503.

29. Toba, H. (2005). A tight flow control for job-shop fabrication lines with finite buffers. IEEE Transactions on Automation Science \& Engineering, 2(1), 78-83.

30. Trochim, M. K. (2001). The research methods knowledge base. Cincinnati, OH: Atomic Dog Publishing.

31. Weng, M. X., \& Halying, R. (2006). An efficient priority rule for scheduling job shops to minimize mean tardiness. IIE Transactions, 38(9), 789-795.

32. Wu, Z., \& Weng, M. X. (2005). Multiagent scheduling method with earliness and tardiness objectives in flexible job shops. IEEE Transactions on Systems, Man \& Cybernetics, 35(2), 293-301. 